\title{
Research productivity and academics' conceptions of research
}

\author{
Angela Brew ${ }^{1,2} \cdot$ David Boud $^{3,4,8} \cdot$ Sang Un Namgung ${ }^{5} \cdot$ \\ Lisa Lucas $^{6} \cdot$ Karin Crawford $^{7}$
}

(C) Springer Science+Business Media Dordrecht 2015

\begin{abstract}
This paper asks the question: do people with different levels of research productivity and identification as a researcher think of research differently? It discusses a study that differentiated levels of research productivity among English and Australian academics working in research-intensive environments in three broad discipline areas: science, engineering and technology; social science and humanities; and medicine and health sciences. The paper explores the different conceptions of research held by these academics in terms of their levels of research productivity, their levels of research training, whether they considered themselves an active researcher and a member of a research team, and their disciplinary differences.
\end{abstract}

Angela Brew

angela.brew@mq.edu.au

David Boud

david.boud@uts.edu.au

Sang Un Namgung

namgung1@empas.com

Lisa Lucas

lisa.lucas@bristol.ac.uk

Karin Crawford

kcrawford@lincoln.ac.uk

1 Learning and Teaching Centre, Macquarie University, Sydney, Australia

2 The University of Sydney, Sydney, Australia

3 Centre for Research in Assessment and Digital Learning, Deakin University, Melbourne, Australia

4 Faculty of Arts and Social Science, University of Technology Sydney, Sydney, Australia

5 Institute of Jeonbuk Education Policy, Chonju, South Korea

6 Graduate School of Education, The University of Bristol, Bristol, UK

7 Educational Development and Enhancement Unit, The University of Lincoln, Lincoln, UK

8 Institute for Work-Based Learning, Middlesex University, London, UK 
Keywords Researchers - Views of research $\cdot$ Research training

\section{Introduction}

Over the past two decades, national research assessments, international league tables and changing patterns of government research funding have led universities to increase emphasis on the quality and quantity of research and expect that more of their academics should be research-active. This has been accompanied by an upsurge of studies examining various aspects of the nature of research. Several trends are discernable. Firstly, studies of factors that contribute to research productivity have intensified within academic disciplines and across countries with increasing emphasis on how it should be developed (e.g. Serenko and Bontis 2004; Grapin et al. 2013). Secondly, and relatedly, there has been an emphasis on the contribution of doctoral students to research productivity (Boud and Lee 2009). Thirdly, there has been a growth in emphasis on a broader view of research as more than just publication, looking at the researcher role, researcher identification, research collaboration, research management and the contribution of undergraduates to research (e.g. Brew and Lucas 2009; Kyvik 2013; Vermunt 2005). Fourthly, there has developed a distinct and hitherto separate literature considering what research is understood to be. This work has explored the conceptions of research of senior researchers, undergraduates and doctoral students and their supervisors and has linked to conceptions of teaching (e.g. Åkerlind 2008; Brew 2001; Prosser et al. 2008).

In this paper, we aim to bring together several of these strands. Specifically, we aim to establish how and whether academics with differing levels of research productivity think of research in different ways. We question whether there are ways of thinking about research that are associated with academics being more productive than others and we explore mechanisms associated with research as a self-generating endeavour. We argue that some ways of thinking about research are characterised by a continual cycle of performativity and high levels of research productivity and that other ways of viewing research are associated with lower levels of productivity and work against academics being active independent researchers.

The paper draws on a study designed to illuminate how academics in different contexts with different career orientations, interpret and position themselves. Archer (2007) argues that social structures and situations provide arenas where people pursue their personal projects and develop their social identity. Social situations are ambiguous and present a complex variety of conflicting opportunities for growth and development and for the pursuit of various personal objectives; a point much of the literature on the nature of research neglects to consider. Archer argues that internal conversations are the means by which humans critically reflect and engage in emotional commentaries on their concerns. These internal conversations are deeply affected by the situations in which people find themselves and the discourses available to them. Being in society "rebounds" on us and we experience both its constraints and what it enables. This affects who we become and the social identities we achieve (Archer 2007).

Whether academics become active researchers could well be influenced by what understandings of research are available and what they understand research to be. So in this paper, we consider the relationship between academics' productivity in research and identification as a researcher on the one hand and what academics think research is on the 
other. The literature on what we know about contributory factors in research productivity and on how academics think about research provide starting points. We then discuss the methodology and findings of the current study.

\section{Research productivity}

Numerous studies have been carried out to examine factors that contribute to researcher productivity. Potential factors have been suggested, and the complexity of variance explained by any one factor has led to an increasing number of multivariate and complex statistical analyses. Factors include:

- institutional features (type and size of institution, departmental climate, funding, laboratory size, etc.; Dever and Morrison 2009; Edgar and Geare 2013; Smeby and Try 2005);

- demographic variables including gender, family size and age of children (e.g. Fox 2005; Stack 2004), overseas trained (e.g. Kim et al. 2011);

- academic capabilities and confidence, and self-efficacy (e.g. Quimbo and Sulabo 2014);

- choice of topic (Fisher 2005); and

- various social aspects such as workload, time spent, level and type of communication and supervision of doctoral students (e.g. Lee and Bozeman 2005).

These studies are bedeviled by the challenges of measuring research productivity within different institutions and disciplines. The literature records a variety of ways in which data are obtained, for example, whether by self-report of academics or published statistics and by different kinds of measures, for example, publication counts over the lifetime of the researcher or during a particular period, use of citations, types of publications counted, how dual authorship is treated, and so on (Brew and Boud 2009). Having collected the data, there are a number of issues regarding its interpretation. This is particularly a problem when comparing findings across disciplines or across countries, as disciplinary and national publication practices vary (see, for example, Padilla-Gonzalez et al. 2011).

While institutional and demographic factors and social structures in which academics operate provide a context for the development of research, within universities, there are implicit and explicit messages about research, teaching, administration and community service; what academics should pursue; and how they should position themselves as academics. These can be ambiguous and may be contradictory. Our argument is that how the context is interpreted by academics determines whether individuals develop or sustain research productivity. The meanings academics attach to research (as well as teaching, administration and community service) depend on their different responses to the various situations in which they find themselves. Their responses also depend on the meanings these contexts make possible and how in turn they respond and thereby position themselves as researchers or teachers. We argue that there are some views of research that are more likely to lead to high levels of research productivity than others; that academics' conceptions of the environment they are in, of their own goals and capabilities and what they understand research to be are central to the research productivity of individuals and therefore of institutions. Yet, we have been unable to find any studies of the relationship between levels of research productivity and identification as a researcher on the one hand and how academics think about and view research on the other. 


\section{Conceptions of research}

The body of work that focuses on how research is understood is as problematic as studies of research productivity. This work is variously referred to as "conceptions", "views", "experiences" or "understandings" of research. Åkerlind (2008) argues that such work tends to confuse four different objects of study: (a) research intentions or who is affected by the research, (b) research outcomes, (c) research questions and (d) research processes. She suggests that there are differences in the findings of studies investigating these different aspects consequent upon their differing objects of study. This work also differs in the subjects of the investigation, whether senior researchers (Brew 2001); undergraduate students (Meyer et al. 2005); doctoral students (Kiley and Mullins 2005; Stubb et al. 2014); managers; or a combination (Bryans and Mavin 2006).

Additional differences in foci include whether the emphasis is on conceptions of what research is (Brew 2001), conceptions of research work (Stubb et al. 2014), conceptions of being a researcher (Åkerlind 2008), conceptions of research subject matter (Prosser et al. 2008) or conceptions of success in research (Bowden et al. 2005). Akerlind (2008) examines academics' understandings of being a researcher, contending that people's views of research intentions, outcomes, questions and processes will be consistent with their understandings of being a researcher. Vermunt (2005) points to the question of whether conceptions of research change over time. Students may be different in this respect from more experienced researchers. There appears to be some evidence that this is the case (e.g. Stubb et al. 2014).

A notable feature of studies of conceptions of research is a conflation of traditional ideas about research methods with the conceptions people actually hold. So, for example, the categories of Meyer et al. (2005) "analytic and systematic inquiry", "finding the truth", "information gathering" and also Kiley and Mullins' (2005) "academic scholarship" describe what researchers do. These are more akin to definitions of research than some of the more metaphorical categories, e.g. the journey conception (found in Brew 2001; Bryans and Mavin 2006; Stubb et al. 2014; Visser-Wijnveen et al. 2009). Further, it is clear that different methodologies used to examine understandings of research lead to different types of categories, e.g. images (Bryans and Mavin 2006), statistical analysis (Meyer et al. 2005) or through different types of phenomenography (discursive; experimental; naturalistic; hermeneutic; or phenomenological) (see Hasselgren and Beach 1997 for a description of the different types).

This discussion highlights difficulties in research that attempts to understand how academics understand the nature of research. However, it is important to understand how students' and supervisors' conceptions of research differ because discrepancies are likely to slow thesis completion. It is also important to understand how more established researchers think about research. Their views influence policies and practices, e.g. funding decisions and committee discussions. Different conceptions can lead to disagreements and, in extreme cases, conflict.

There are a number of questions that this body of work raises. These include the extent to which the categories are more general across the population of academics, and whether academics with particular attributes have similar conceptions of research, or, more specifically, whether there is a relationship between researcher productivity and how the researcher conceptualises or understands research. These are the questions addressed here. Clearly, as argued above, the ways in which conceptions of research are negotiated and developed is related to the contexts in which researchers find themselves (Stubb et al. 
2014). A step on the way to appreciating this is understanding the role of specific views of research in relation to research productivity and identification as a researcher which is the focus of this paper.

Our aim is not to try to provide an overview of the various conceptions of research proposed, nor to provide a synthesis. Rather, as Stubb et al. (2014, p. 253) point out, "studies provide a good overall picture of the same phenomenon portrayed from different angles". Brew's (2001) study was intended to understand what was in the forefront of researchers' minds (what researchers thought about) when asked to talk about their research. She interviewed fifty-seven senior researchers with substantial track records in publication and in gaining research grants and found they were differentiated according to four conceptions of research which were given metaphorical names. Since a number of the facets of Brew's original study have reappeared in different guises in later work (e.g. Stubb et al. 2014, p. 252; Vermunt 2005, p. 330), it seemed appropriate to build on that study and relate the findings to issues of researcher productivity and identification as a researcher.

Brew (2001) analysed transcripts phenomenographically. This qualitative research methodology is designed to map the variation in the range of ways that a phenomenon (in this case "research") is experienced and to demonstrate the structural similarities and differences in ways of viewing the phenomenon, i.e. how the resultant categories are related (see Marton and Booth 1997). Brew (2001) found that senior researchers' conceptions of research were differentiated according to four "conceptions" which were given metaphorical names (domino, trading, layer and journey). She found that the four categories were related to two dimensions of variation. Firstly, whether researchers themselves appeared to be in the forefront of their minds (present in awareness) or whether they presented research impersonally as if the researcher did not exist (as if absent from awareness). And secondly, whether the research was oriented internally or externally (see Table 1).

Table 1 Relationships between conceptions of research (Brew 2001, p. 281)

\begin{tabular}{|c|c|c|}
\hline & $\begin{array}{l}\text { External product orientation where the } \\
\text { intention is to produce an outcome. } \\
\text { Tends to be atomistic and synthetic }\end{array}$ & $\begin{array}{l}\text { Internal process orientation where the } \\
\text { intention is to understand. } \\
\text { Tends to be holistic and analytical }\end{array}$ \\
\hline $\begin{array}{l}\text { Researcher is } \\
\text { present in } \\
\text { awareness }\end{array}$ & $\begin{array}{l}\text { Trading conception } \\
\text { Research is viewed as a social } \\
\text { phenomenon } \\
\text { Emphasis is on the finished products, e.g. } \\
\text { publications, research grants or social } \\
\text { benefits which are exchanged for money, } \\
\text { prestige or recognition } \\
\text { Research is viewed in terms of the } \\
\text { relationships with other people which are } \\
\text { brought about }\end{array}$ & $\begin{array}{l}\text { Journey conception } \\
\text { Research is viewed holistically } \\
\text { Content, issues and processes are integral } \\
\text { to the researcher's life and presented as a } \\
\text { personal journey of discovery } \\
\text { The researcher grows or is transformed by } \\
\text { this }\end{array}$ \\
\hline $\begin{array}{l}\text { Researcher is as } \\
\text { if absent from } \\
\text { awareness }\end{array}$ & $\begin{array}{l}\text { Domino conception } \\
\text { Research is described as a series (often a } \\
\text { list) of separate tasks, events, things, } \\
\text { activities, problems, techniques, } \\
\text { experiments which are then are } \\
\text { combined in a linear way, e.g. to provide } \\
\text { an explanation, solve a problem or } \\
\text { answer a question }\end{array}$ & $\begin{array}{l}\text { Layer conception } \\
\text { Reality is presented as a surface and the } \\
\text { researcher is concerned with uncovering } \\
\text { what lies beneath that surface } \\
\text { What is found, may be considered to } \\
\text { exist, (discovery), or may be simply a } \\
\text { better explanation, or may be a creation } \\
\text { to illuminate the surface reality }\end{array}$ \\
\hline
\end{tabular}




\section{Methods}

We conducted an online survey of academics from research-intensive university environments in six Australian and six English universities. Institutions were selected using national statistics of research performance in the selected disciplinary groups so as to provide a mix of universities with research-intensive areas (recognising that areas of research intensity exist even when a university as a whole is not designated research intensive). So Australian universities (surveyed in 2008) included the Group of Eight, Innovative Research Universities (IRU) and the Australian Technology Network, while English universities chosen included Russell Group, post-92 and redbrick universities (surveyed in 2012). Academics surveyed were from three broad disciplinary groups: sciences, engineering and technology; humanities and social sciences; and medical and health sciences. Respondents were identified through staff lists on websites. Approximately 4000 academics were surveyed in each country. Before the analysis, respondents who identified as not on teaching and research contracts were eliminated as were responses with insufficient data. This left a total of 2163 usable responses for the analysis.

Academics completing the survey were asked five sets of questions relating to their (1) academic area, research and teaching responsibilities, priorities and engagement; (2) levels of research productivity and the extent to which they identified as a researcher; (3) Ph.D completion and training and development related to research, teaching and administration/management; (4) views of research and teaching; and (5) biographical details (e.g. discipline, gender and age; see Table 2).

With regard to research productivity, as mentioned above, there are many ways of calculating it. An anonymous survey precluded using published statistics. We recognised the limitations of self-report and of counting publications without taking account of any quality indicators. However, it was clear that any measures we used would have limitations, so we chose to ask survey respondents to indicate the number of their specific items

Table 2 Description of the sample

\begin{tabular}{|c|c|c|c|c|c|c|}
\hline & $\begin{array}{l}\text { Australia } \\
n\end{array}$ & $(\%)$ & $\begin{array}{l}\mathrm{UK} \\
n\end{array}$ & $(\%)$ & $\begin{array}{l}\text { Combined } \\
n\end{array}$ & $(\%)$ \\
\hline \multicolumn{7}{|l|}{ Gender } \\
\hline Male & 602 & 55 & 638 & 60 & 1240 & 57 \\
\hline Female & 496 & 45 & 427 & 40 & 923 & 43 \\
\hline \multicolumn{7}{|l|}{ Age } \\
\hline Under 35 & 85 & 8 & 115 & 11 & 200 & 9 \\
\hline $35-45$ & 337 & 31 & 359 & 34 & 696 & 32 \\
\hline $46-54$ & 349 & 32 & 283 & 27 & 632 & 29 \\
\hline $55+$ & 268 & 24 & 212 & 20 & 480 & 22 \\
\hline $\mathrm{n} / \mathrm{a}$ & 59 & 5 & 96 & 9 & 155 & 7 \\
\hline \multicolumn{7}{|l|}{ Discipline } \\
\hline Science, engineering and technology & 299 & 27 & 349 & 33 & 648 & 30 \\
\hline Arts and social science & 583 & 53 & 603 & 57 & 1186 & 55 \\
\hline Health sciences & 216 & 20 & 113 & 11 & 329 & 15 \\
\hline Total & 1098 & 100 & 1065 & 100 & 2163 & 100 \\
\hline
\end{tabular}


of publications (e.g. books, book chapters, journal articles, conference presentations) in the 5 years prior to completing the survey. Whether or not publications were jointly authored was not identified. We also asked respondents how many research grants they had applied for and obtained in the same 5 years.

In determining levels of researcher productivity, first we calculated a publication score for each respondent on each type of publication and overall. Single authored books were weighted $5 \times$ articles. A score for the number of research grants applied for and/or obtained was also calculated. We then ranked academics to derive levels of research productivity. Initially, when this was done for the Australian data alone, it was found that the proportion of academics in the high research productive group was significantly larger in science, engineering and technology than in the other two areas. Indeed, the Games-Howell post hoc tests revealed significant differences between the science, engineering and technology group and the other two groups $[F=(2,713)=17.8, p=0.001]$ (Brew and Boud 2009). This reflects the skewed distribution of disciplines in terms of volume of research productivity, with sciences and technology publishing a much larger number of shorter papers often with multiple authors. Therefore, for the UK and the combined data reported in this paper, we chose to take account of disciplinary differences in publication practices. For each disciplinary group, we constituted a "high research productive" group consisting of respondents designated high on publications and high on grants; a second "low research productive" group from respondents low on publications and on grants; and a third medium group based on comparing means and standard deviations. It was assumed that the proportion of high, medium and low research productive academics were similar in each broad area so the thresholds were adjusted accordingly.

Three measures of identification as a researcher were then used: (1) whether academics considered themselves "research-active" (irrespective of whether their university defined them as such) (yes or no); (2) whether they considered they were an active member of a research team inside their university (yes or no); and (3) whether they considered they were an active member of a research team in another university, in industry or internationally (yes or no). We then related research productivity levels to these measures (see Table 3).

With regard to conceptions of research, a set of six statements derived from each of Brew's (2001) four conceptions of research (domino, trading, layer and journey) were utilised. Statements were chosen because they expressed essential features of the conception (see Table 5). The order of statements was randomised and respondents were asked to indicate agreement or disagreement on a five-point scale (Statements on conceptions of teaching derived from Prosser and Trigwell (1999) were similarly utilised, but discussion

Table 3 Three levels of research productivity by discipline

\begin{tabular}{|c|c|c|c|c|c|}
\hline & \multicolumn{4}{|c|}{ Main academic area } & \multirow[t]{2}{*}{$x^{2} / p$} \\
\hline & $\begin{array}{l}\text { Science, } \\
\text { engineering } \\
\text { and technology }\end{array}$ & $\begin{array}{l}\text { Social sciences, } \\
\text { humanities } \\
\text { and the arts }\end{array}$ & $\begin{array}{l}\text { Medicine } \\
\text { and health } \\
\text { sciences }\end{array}$ & Total & \\
\hline \multicolumn{6}{|c|}{ Research productivity } \\
\hline High in research & $114(17.6 \%)$ & $220(18.5 \%)$ & $71(21.6 \%)$ & $405(18.7 \%)$ & $5.138 / .273$ \\
\hline $\begin{array}{l}\text { Medium in } \\
\text { research }\end{array}$ & $383(59.1 \%)$ & $689(58.1 \%)$ & $171(52.0 \%)$ & $1243(57.5 \%)$ & \\
\hline Low in research & $151(23.3 \%)$ & $277(23.4 \%)$ & $87(26.4 \%)$ & $515(23.8 \%)$ & \\
\hline Total & $648(100.0 \%)$ & $1186(100.0 \%)$ & $329(100.0 \%)$ & $2163(100 \%)$ & \\
\hline
\end{tabular}


of these falls outside this paper). This strategy was adopted recognising the absence in the literature of well-developed quantitative measures for exploring conceptions, views or experiences of research. Then, factor analyses on conceptions of research and teaching were conducted. The final stage was to relate the three productivity groupings to the resultant factors.

\section{Findings}

\section{Researcher productivity}

Data show that in a total of 2163 respondents, 405 (18.7) academics are classified as high research productive, while $1243(57.5 \%)$ are medium and $515(23.8 \%)$ are low research productive. Among three academic areas, medicine and health sciences has the highest percentage of respondents high in research productivity $(71(21.6 \%))$ and the lowest percentage of respondents low in research productivity $(87(26.4 \%))$. However, there was no significant differences between academic areas $(p=.273)$.

In examining the relationship of these different levels of research productivity to other attributes, we found a significant association between research productivity and academic levels $\left(x^{2}(4)=405.194, p=.000\right)$. As expected, professors are more research productive than lecturers. Cross-tabulating Australian and English levels of research productivity, we did not find any significant differences.

\section{Identification as a researcher}

We examined whether academics identified as a researcher irrespective of their stated levels of research productivity and cross-tabulated their scores on each of the three measures (considering themselves "research-active"; considering themselves to be an active member of a local research team; and considering themselves to be an active member of an external research team) with their levels of research productivity (see Table 4).

Table 4 Research productivity and identity (\%)

\begin{tabular}{|c|c|c|c|c|c|}
\hline $\begin{array}{l}\text { Identity } \\
\text { measures }\end{array}$ & $\begin{array}{l}\text { High research } \\
\text { productivity }\end{array}$ & $\begin{array}{l}\text { Medium research } \\
\text { productivity }\end{array}$ & $\begin{array}{l}\text { Low research } \\
\text { productivity }\end{array}$ & Total & $x^{2} / p$ \\
\hline \multicolumn{6}{|c|}{ Consider they are "research-active" } \\
\hline Yes & $402(99.8)$ & $1,161(93.6)$ & $314(66.0)$ & $2120(100)$ & $319.663 / .000^{*}$ \\
\hline No & $1(0.2)$ & $80(6.4)$ & $162(34.0)$ & & \\
\hline \multicolumn{6}{|c|}{ Member of research team in university } \\
\hline Yes & $362(89.6)$ & $913(73.9)$ & $215(45.3)$ & $2114(100)$ & $223.255 / .000 *$ \\
\hline No & $42(10.4)$ & $322(26.1)$ & $260(54.7)$ & & \\
\hline \multicolumn{6}{|c|}{ Member of external research team } \\
\hline Yes & $343(84.7)$ & $779(63.0)$ & $150(31.6)$ & $2115(100)$ & $266.681 / .000^{*}$ \\
\hline No & $62(15.3)$ & $457(37.0)$ & $324(68.4)$ & & \\
\hline
\end{tabular}

$* p<.01$ 
The data suggest that many academics appear to identify as a researcher while undertaking considerably less research than their peers. When asked whether they identified as a member of a research team in their own institution, $1490(70.5 \%)$ responded that they did. This included $362(89.6 \%)$ academics in the high research productive group but 215 $(45.3 \%)$ academics in the low research productive group. The difference between groups was significant $\left(x^{2}(2)=223.3, p<.001\right)$. While $343(84.7 \%)$ academics in the high research productive group regarded themselves as active members of an external research team, only $150(31.6 \%)$ academics in the low research productive group regarded themselves as such. Again, $\chi^{2}$ analysis reveals that the differences between groups was significant $\left(x^{2}(2)=266.7, p<.001\right)$.

\section{How academics understand research}

The next step was to examine conceptions of academics with different levels of research productivity and whether they identified as researchers in terms of their understandings of research. Factor analyses on conceptions of research were carried out. For the exploratory factor analysis, principal components analysis (PCA) and a varimax rotation method were used and Brew (2001) used in interpreting the resulting factors. The domino and layer conceptions were not distinct in the analysis. It appeared that they were combined in Factor 1. Among 24 items, ten items were deleted from the previous four categories as they insufficiently discriminated. Finally, 14 items were extracted for the factor analysis. The analyses were carried out first on the Australian, then on the UK and finally on the combined data (presented here). The resultant factors were the same in each case.

The initial eigenvalues showed that the first factor explained $20.2 \%$ of the variance. The second factor explained $18.7 \%$ of the variance and the third factor explained $15.6 \%$ of the variance. The three factors explained $54.5 \%$ of the variance.

Brew (2001) describes the domino and layer views as distinct from the trading and the journey views in that they present research as if it were absent from the researcher (see Table 1). This differentiates Factor 1 and Factor 2 from Factor 3 in the current findings; Factors 1 and 2 being focused on the person of the researcher and Factor 3 presenting research as if the researcher was absent from awareness. In hindsight, it can be seen that statements comprising Factor 3 do not sufficiently differentiate the internal-external dimension of variation which distinguishes the domino and the layer conception in the earlier research. This may explain why three and not four factors were found (see Table 5).

\section{Relationship of researcher productivity to conceptions of research}

The next step was to determine whether there were differences in how high research productive academics and low research productive academics thought about research (Table 6).

All three conceptions were found to be represented in all research productivity levels. However, in a test of the analysis of variance (ANOVA) significant differences for Factor 1 (trading) were found between research productivity categories $(F(2,1990)=151.71$, $p<.001)$. As the assumption of homogeneity of variance was violated, Welch F-ratio is used. The result suggests that Factor 1 (trading) is significantly related to research productivity. The trading conception includes a specific focus on publication, but it also includes an emphasis on the social networking aspects of research. The other two views did not have a significant effect on research productivity. Dunnett T3 post hoc tests revealed significant differences between all groups $(p<.001)$. The high research productivity group 


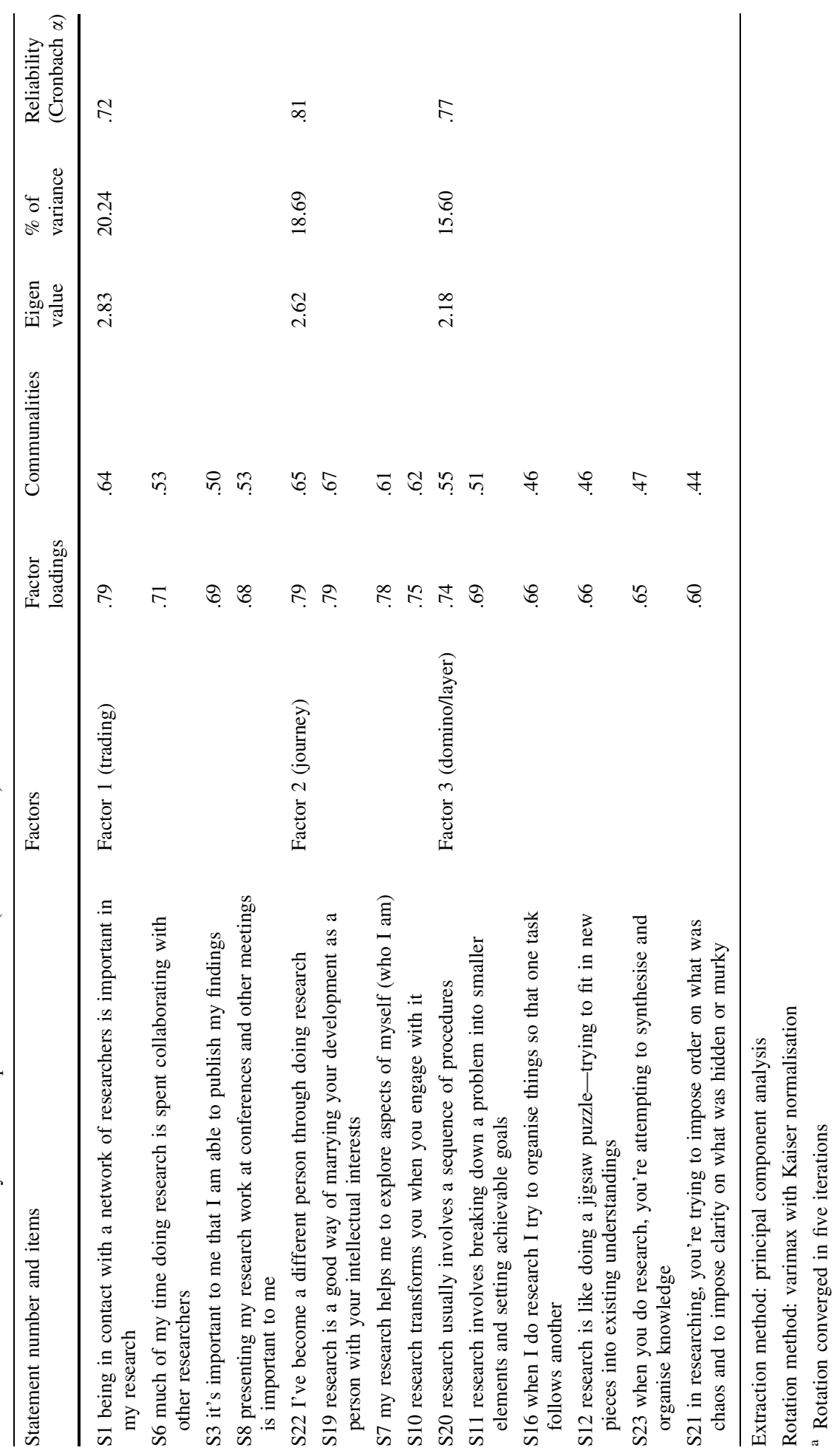


Table 6 Results of ANOVA and post hoc test for conceptions by research productivity (combined Australian and English data)

\begin{tabular}{|c|c|c|c|c|c|c|}
\hline Views of research & Research productivity & $n$ & Mean & SD & F/Sig. & $\begin{array}{l}\text { Post hoc test } \\
\text { (Dunnett T3) }\end{array}$ \\
\hline \multirow[t]{4}{*}{ Domino and layer } & High research productivity(a) & 388 & 3.56 & .71 & $2.40 / .091$ & \\
\hline & $\begin{array}{c}\text { Medium research } \\
\text { productivity(b) }\end{array}$ & 1126 & 3.47 & .72 & & \\
\hline & Low research productivity(c) & 419 & 3.47 & .76 & & \\
\hline & Total & 1933 & 3.49 & .73 & & \\
\hline \multirow[t]{4}{*}{ Journey } & High research productivity(a) & 391 & 3.18 & 1.00 & $2.40 / .091$ & \\
\hline & $\begin{array}{c}\text { Medium research } \\
\text { productivity(b) }\end{array}$ & 1139 & 3.06 & 1.00 & & \\
\hline & Low research productivity(c) & 418 & 3.12 & 1.05 & & \\
\hline & Total & 1948 & 3.09 & 1.01 & & \\
\hline \multirow[t]{4}{*}{ Trading } & High research productivity(a) & 393 & 4.16 & .64 & $151.71 / .000 *$ & $a>b>c$ \\
\hline & $\begin{array}{c}\text { Medium research } \\
\text { productivity(b) }\end{array}$ & 1174 & 3.79 & .79 & & \\
\hline & Low research productivity(c) & 426 & 3.21 & .92 & & \\
\hline & Total & 1993 & 3.74 & .85 & & \\
\hline
\end{tabular}

$* p<.001$

is associated with a strong focus on the trading conception (see Table 6). This was the case with both English and Australian data. Therefore, Table 6 presents the combined data.

As seen earlier, identifying as a researcher was not necessarily associated with being research productive in terms of publications and research grants. We explored the views of research held by academics who identified as a researcher (active researcher) and those who did not (non-active researcher) and found that active researchers are more likely to have a trading view than non-active researchers. Members of research teams are much more likely than people not in research teams to have a trading view than a domino/layer or journey view. Similarly, those involved in research teams outside their university are also much more likely to have a trading view (see Tables 7, 8, 9). Again, no differences were found across countries.

Table 7 Results of $t$ test for conceptions by research activeness

\begin{tabular}{|c|c|c|c|c|c|}
\hline Research activeness & $n$ & Mean & $\mathrm{SD}$ & $t$ & $p$ \\
\hline \multicolumn{6}{|l|}{ Trading } \\
\hline Active researcher & 1791 & 3.83 & .78 & 13.044 & $.000 * *$ \\
\hline Non-active researcher & 199 & 2.90 & .97 & & \\
\hline \multicolumn{6}{|l|}{ Journey } \\
\hline Active researcher & 1753 & 3.13 & 1.01 & 5.052 & $.000 * *$ \\
\hline Non-active researcher & 192 & 2.75 & .95 & & \\
\hline \multicolumn{6}{|l|}{ Domino/layer } \\
\hline Active researcher & 1739 & 3.50 & .73 & 1.631 & .103 \\
\hline Non-active researcher & 191 & 3.41 & .75 & & \\
\hline
\end{tabular}

$* p<.05 ; * * p<.01$ 
Table 8 Results of $t$ test for conceptions by research team in a university

\begin{tabular}{|c|c|c|c|c|c|}
\hline Research team inside & $n$ & Mean & SD & $t$ & $p$ \\
\hline \multicolumn{6}{|l|}{ Trading } \\
\hline Research team & 1429 & 3.94 & .72 & 16.586 & $.000 * *$ \\
\hline Non-research team & 556 & 3.22 & .93 & & \\
\hline \multicolumn{6}{|l|}{ Journey } \\
\hline Research team & 1398 & 3.12 & .99 & 2.297 & $.022 *$ \\
\hline Non-research team & 542 & 3.01 & 1.06 & & \\
\hline \multicolumn{6}{|l|}{ Domino/layer } \\
\hline Research team & 1383 & 3.53 & .70 & 3.539 & $.000 * *$ \\
\hline Non-research team & 542 & 3.3902 & .78 & & \\
\hline
\end{tabular}

$* p<.05 ; * * p<.01$

Table 9 Results of $t$ test for conceptions by research team outside the university

\begin{tabular}{|c|c|c|c|c|c|}
\hline Research team outside & $n$ & Mean & $\mathrm{SD}$ & $t$ & $p$ \\
\hline \multicolumn{6}{|l|}{ Trading } \\
\hline Research team & 1213 & 4.02 & .69 & 19.788 & $.000 * *$ \\
\hline Non-research team & 774 & 3.29 & .87 & & \\
\hline \multicolumn{6}{|l|}{ Journey } \\
\hline Research team & 1184 & 3.19 & 1.00 & 5.235 & $.000 * *$ \\
\hline Non-research team & 758 & 2.95 & 1.01 & & \\
\hline \multicolumn{6}{|l|}{ Domino/layer } \\
\hline Research team & 1174 & 3.52 & .73 & 2.347 & $.019 *$ \\
\hline Non-research team & 753 & 3.44 & .73 & & \\
\hline
\end{tabular}

$* p<.05 ; * * p<.01$

Table 10 Results of $t$ test for conceptions by doctorates

\begin{tabular}{|c|c|c|c|c|c|}
\hline Doctorate & $n$ & Mean & SD & $t$ & $p$ \\
\hline \multicolumn{6}{|l|}{ Trading } \\
\hline Doctorate & 1657 & 3.85 & .76 & 11.437 & $.000 * *$ \\
\hline Non-doctorate & 334 & 3.17 & 1.04 & & \\
\hline \multicolumn{6}{|l|}{ Journey } \\
\hline Doctorate & 1617 & 3.09 & 1.01 & -.424 & .672 \\
\hline Non-doctorate & 329 & 3.12 & .98 & & \\
\hline \multicolumn{6}{|l|}{ Domino/layer } \\
\hline Doctorate & 1606 & 3.49 & .72 & .504 & .614 \\
\hline Non-doctorate & 325 & 3.47 & .76 & & \\
\hline
\end{tabular}

$* p<.05 ; * * p<.01$

We also examined whether academics with doctorates $(n=1754)$ have different ideas about research to those without and found that those with doctorates were more likely to perceive research in terms of the trading view than those without. Further, the 
Table 11 Disciplinary differences in conceptions of research (combined English and Australian data)

\begin{tabular}{|c|c|c|c|c|c|c|}
\hline $\begin{array}{l}\text { Dependent } \\
\text { variables }\end{array}$ & Disciplines & $n$ & Mean & SD & $F /$ Sig. & $\begin{array}{l}\text { Post } \\
\text { hoc test }\end{array}$ \\
\hline \multirow[t]{4}{*}{ Trading view } & $\begin{array}{l}\text { Science, engineering and } \\
\text { technology(a) }\end{array}$ & 600 & 3.93 & .78 & \multirow[t]{4}{*}{$34.490 / .000 * *$} & \multirow[t]{4}{*}{$\mathrm{a}, \mathrm{c}>\mathrm{b}$} \\
\hline & $\begin{array}{l}\text { Social sciences, humanities and } \\
\text { the } \operatorname{arts}(\mathrm{b})\end{array}$ & 1092 & 3.60 & .85 & & \\
\hline & Medicine and health sciences(c) & 301 & 3.86 & .87 & & \\
\hline & Total & 1993 & 3.74 & .85 & & \\
\hline \multirow[t]{4}{*}{ Journey view } & $\begin{array}{l}\text { Science, engineering and } \\
\text { technology(a) }\end{array}$ & 581 & 2.89 & .99 & \multirow[t]{4}{*}{$24.748 / .000 * *$} & \multirow[t]{4}{*}{$b>a, c$} \\
\hline & $\begin{array}{l}\text { Social sciences, humanities and } \\
\text { the } \operatorname{arts}(\mathrm{b})\end{array}$ & 1073 & 3.23 & 1.02 & & \\
\hline & Medicine and health sciences(c) & 294 & 3.00 & .93 & & \\
\hline & Total & 1948 & 3.09 & 1.01 & & \\
\hline \multirow[t]{4}{*}{$\begin{array}{l}\text { Domino and layer } \\
\text { view }\end{array}$} & $\begin{array}{l}\text { Science, engineering and } \\
\text { technology(a) }\end{array}$ & 578 & 3.48 & .70 & \multirow[t]{4}{*}{$14.350 / .000 * *$} & \multirow[t]{4}{*}{$c>a, b$} \\
\hline & $\begin{array}{l}\text { Social sciences, humanities and } \\
\text { the } \operatorname{arts}(\mathrm{b})\end{array}$ & 1061 & 3.44 & .76 & & \\
\hline & Medicine and health sciences(c) & 294 & 3.68 & .65 & & \\
\hline & Total & 1933 & 3.49 & .73 & & \\
\hline
\end{tabular}

$* p<.05 ; * *<<.01$

ideas of those with a doctorate appeared to be more consistent than those without (see Table 10).

Although no significant differences in views of research and age or length of service of the academics were found, some disciplinary differences were noticed. Although some small country differences were discernible, in both countries there were similar small statistically significant differences between disciplines in terms of the conceptions of research that the academics held. The mean score on the trading view, for science, engineering and technology, and medicine and health sciences was higher than that of social sciences, humanities and arts. The mean score of social sciences, humanities and arts on the journey view was higher than other two groups. The domino/layer view was higher for medicine and health sciences than the other two groups (see Table 11).

Academics in medicine and health sciences are more likely to have a domino/layer view than academics in the other two groups. Academics in medicine and health sciences were also more likely to have domino and layer and trading views of research, while academics in social sciences, humanities and the arts were more likely to have a journey view than academics in medicine and health sciences and science, engineering and technology. Medicine and health sciences and science engineering and technology academics were more likely to have a trading view than academics in the social sciences.

\section{Discussion}

Following Archer (2000), we suggested that the academic environment both constrains and enables depending on how people interpret situations in which they find themselves. Levels of research productivity were found to be related to how academics viewed research. We 
see here that academics have different levels of research productivity and that these levels of research productivity are related to but not dependent upon identifying as a researcher. Productive academics are likely to identify as research-active and to belong to research teams, but it is not the case that those with low levels of research productivity do not identify as active researchers. As Lucas (2006) has argued, being defined as non-researchactive does not necessarily mean that academics do not do research. It may simply mean that the research they are doing is not measured by current metrics.

In some respects, the findings presented are not unexpected. Those who focus on research as a process of publication publish more research. Indeed, it has often been suggested that government and university policy tends to focus attention on this view so this provides the social setting in which such a practice can flourish. However, publication is not all there is to the trading view of research (Factor 1). It embodies the idea of research as a social phenomenon. As important to this view as a focus on publication, are ideas of research as involving social networks, reputation through going to conferences, and collaborating with other researchers. There is a focus on the career of the researcher and the external products required to support and sustain a reputation within the social (research) context. These elements do not figure directly in discourses of research productivity, though they are important at the very least in ensuring success in research grant applications.

Unlike other conceptions of research, the trading view relates to a self-generating researcher identity. Research develops in the act of publication, networks, collaborations and peer review. These activities support a person's identification as a researcher. They also, in turn, influence performance measures and metrics. When research is viewed as a social phenomenon, then researchers are likely to interact, to recognise each other, to collaborate on joint projects and consequently to cite each other. All of these activities lead to continually increasing levels of performance. This becomes a self-generating endeavour. An interesting question to be explored in future work is whether these self-sustaining aspects of the trading view may create distortions and over time discourage certain kinds of research. In order to address this question, we need to know more about the ways in which the academic environment constrains particular ways of thinking about research and enables others.

This is in contrast to the journey view (Factor 2) where the focus is also on the person of the researcher, but on individual personal development. Brew's (2001) original study was conducted with senior research productive academics. Nevertheless, with the journey view, a person's identification as a researcher appeared diffuse and less focused. An environment where short-term goals, social networks and quick turnaround of publications is the order of the day, does not support this view. Individual scholarship that takes a long time to come to fruition may isolate the researcher and lead to a devaluing of such work in such a context. There can be inherent constraints within this view, which may inhibit publication and networking.

It was found that academics who identified as a researcher and those who had completed a doctorate appeared to have stronger views of particular ideas of research than those without. This is an interesting finding, suggesting that the practice of pursuing research consolidates peoples' views about what is involved. It may be that some academics do not engage in research because they do not have a clear idea as to what it entails.

We also found that doctoral graduates are more likely than those without a doctorate to see research in a trading way. While this may be tempered with disciplinary differences in practices, we may deduce that learning that research is a social phenomenon (often 
involving publication) during doctoral work may be a key to success as a productive researcher again due to the self-generating nature of this view.

With the domino/layer view, the focus is not on the person but on techniques to complete or understand the project or the data. The person's identification as a researcher is not a primary concern. This view does not automatically lead to high levels of publication and may result in the opposite: it is the study that is central, not the products of the study as such. It would be interesting to be able to differentiate those academics with the domino/ layer view in terms of their internal or external focus as it might be expected that a focus on external products could be associated with higher levels of productivity. However, it was not possible to determine this from our data.

Conceptions of research in this study drew on Brew (2001) which explored underlying ideas about what a group of academics think research is. However, as we noted in discussing the literature on conceptions or experiences of research above, there are a number of other dimensions of research which might equally well have been used (research intentions or who is affected by the research, research outcomes; research questions or research processes). Further, we are aware that the language of conceptions, views, understandings and experiences of phenomena have been overly associated with the methodology of phenomenography. We have maintained these terms as they are appropriate descriptors for the ideas we have investigated.

However, the close fit with two of Brew's categories of description and the combination of two others, requires comment. It was considered that failure to differentiate the domino and the layer conception in the initial analysis of the Australian data may have been due to the choice of statements for the layer conception which did not sufficiently describe the distinctive features of that conception, namely what Visser-Wijnveen et al. (2009, p. 678) describe as the "excavation" aspects. Therefore, when revising the questionnaire for the English context, it was considered whether to change or add these items. However, this would have made country comparisons impossible. It was therefore decided that for purposes of comparison, the survey items should be kept the same. Accordingly, the factor structure for the UK data was the same as for the combined data (see Table 5). The results suggest, however, that further work to explore these views of research would be worthwhile. This is particularly so given the close fit with levels of research productivity. Notwithstanding the difficulties in measuring research productivity (and our measures are no exception), since conceptions of research have not hitherto been suggested as factors that affect research productivity, our study suggests that more work to explore this relationship could be fruitful. There is a need to understand more about how this relationship plays out within different disciplines and the effects of different measures of research productivity and quality on how academics view research. There is also a need to understand more about the role of research teams and how they play out when teams have different views of research.

\section{Conclusion}

This study has discussed the relationship between researcher productivity and identification as a researcher and suggested that this is not straightforward. It has identified three relatively distinct conceptions of research and suggested that highly productive researchers tend to have a view of research with an emphasis on the career of the researcher where research is viewed as a social phenomenon with publications, presentations and research 
grants traded in academic networks. The study has also suggested that academics who identify as a researcher whether or not they are highly research productive and those with doctorates tend to have stronger, more consistent conceptions of research than those without. Finally, the study has indicated some disciplinary differences in how academics tend to view research.

Further work is now needed to replicate the findings in other studies, and for more studies of organisational and cultural influences and how they might be taken up in particular contexts. We also need studies of different kinds of doctoral practices and those that explore how these may lead to graduates taking up different conceptions of research. Indeed, the processes of identity formation among individuals, how they come to have the conceptions they do and respond to the contexts in which they find themselves, how particular features such as doctoral studies, or disciplinary contexts act to construct particular identities in individuals all require fine-grained in-depth qualitative work some of which is the subject of the next phase of this study.

Acknowledgments Grateful thanks are due to Peter Petocz for providing helpful comments on an earlier draft of this paper. The survey design and its Australian implementation were funded by a grant from The University of Sydney.

\section{References}

Åkerlind, G. S. (2008). An academic perspective on research and being a researcher: An integration of the literature. Studies in Higher Education, 33(1), 17-31.

Archer, M. S. (2000). Being human: The problem of agency. Cambridge: Cambridge University Press.

Archer, M. S. (2007). Making our way through the world: Human reflexivity and social mobility. Cambridge: Cambridge University Press.

Boud, D., \& Lee, A. (Eds.). (2009). Changing practices in doctoral education. London: Routledge.

Bowden, J., Green, P., Barnacle, P., Cherry, N., \& Usher, R. (2005). Academics' ways of understanding success in research activities. In J. A. Bowden \& P. Green (Eds.), Doing developmental phenomenography (pp. 128-144). Melbourne: RMIT University Press.

Brew, A. (2001). Conceptions of research: A phenomenographic study. Studies in Higher Education, 26(2), 271-285.

Brew, A., \& Boud, D. (2009). Understanding academics' engagement with research. In A. Brew \& L. Lucas (Eds.), Academic Research and Researchers (pp. 189-203). London: SRHE and the Open University Press.

Brew, A., \& Lucas, L. (2009). Academic research and researchers. Maidenhead, UK: McGraw Hill, Society for Research into Higher Education and the Open University Press.

Bryans, P., \& Mavin, S. (2006). Visual images: A technique to surface conceptions of research and researchers. Qualitative Research in Organizations and Management, 1(2), 113-128.

Dever, M., \& Morrison, Z. (2009). Women, research performance and work context. Tertiary Education and Management, 15(1), 49-62.

Edgar, F., \& Geare, A. (2013). Factors influencing university research performance. Studies in Higher Education, 38(5), 774-792.

Fisher, R. L. (2005). The research productivity of scientists: how gender, organisation culture and the problem choice process influence the productivity of scientists. Oxford, UK: University Press of America.

Fox, M. (2005). Gender, family characteristics, and publication productivity among scientists. Social Studies of Science, 35(1), 131-150.

Grapin, S. L., Kranzler, J. H., \& Daley, M. L. (2013). Psychology in the schools: Scholarly productivity and impact of school psychology faculty in APA-accredited programs. Psychology in the Schools, 50(1), 87-101.

Hasselgren, B., \& Beach, D. (1997). Phenomenography: A "good for nothing brother" of phenomenology? Higher Education Research and Development, 16(2), 191-202. 
Kiley, M., \& Mullins, G. (2005). Supervisors' conceptions of research: What are they? Scandinavian Journal of Educational Research, 49(3), 245-262.

Kim, D., Wolf-Wendel, L., \& Twombly, S. (2011). International faculty: Experiences of academic life and productivity in U.S. universities. Journal of Higher Education, 82(6), 720-747.

Kyvik, S. (2013). The academic researcher role: Enhancing expectations and improved performance. Higher Education, 65, 525-538.

Lee, S., \& Bozeman, B. (2005). The impact of research collaboration on scientific productivity. Social Studies of Science, 35(5), 673-702.

Lucas, L. (2006). The research game in academic life. Maidenhead, UK: Open University Press and the Society for Research into Higher Education.

Marton, F., \& Booth, S. (1997). Learning and awareness. Mahwah, NJ: Lawrence Erlbaum.

Meyer, J. H. F., Shanahan, M. P., \& Laugksch, R. C. (2005). Students' conceptions of research: I-a qualitative and quantitative analysis. Scandinavian Journal of Educational Research, 49, 225-244.

Padilla-Gonzalez, L., Metcalfe, A. S., Galaz-Fontes, J. F., Fisher, D., \& Snee, I. (2011). Gender gaps in North American research productivity: Examining faculty publication rates in Mexico, Canada, and the U.S. Compare: A Journal of Comparative and International Education, 41(5), 649-668.

Prosser, M., \& Trigwell, K. (1999). Understanding learning and teaching: The experience in higher education. Buckingham: Society for Research in Higher Education and the Open University Press.

Prosser, M., Martin, E., Trigwell, K., Ramsden, P., \& Middleton, H. (2008). University academics' experience of research and its relationship to their experience of teaching. Instructional Science, 36(1), $3-16$.

Quimbo, M.-A. T., \& Sulabo, E. C. (2014). Research productivity and its policy implications in higher education institutions. Studies in Higher Education, 39(10), 1955-1971.

Serenko, \& Bontis, (2004). Meta-review of knowledge management and intellectual capital literature: Citation impact and research productivity rankings. Knowledge and Process Management, 11(3), $185-198$.

Smeby, J. C., \& Try, S. (2005). Departmental contexts and faculty research activity in Norway. Research in Higher Education, 46(6), 593-619.

Stack, S. (2004). Gender, children and research productivity. Research in Higher Education, 45(8), 891-920.

Stubb, J., Pyhältö, K., \& Lonka, K. (2014). Conceptions of research: The doctoral student experience in three domains. Studies in Higher Education, 39(2), 251-264.

Vermunt, J. (2005). Conceptions of research and methodology learning: A commentary on the special issue. Scandinavian Journal of Educational Research, 49(3), 329-334.

Visser-Wijnveen, G. J., Van Driel, J. H., Van der Rijst, R. M., Verloop, N., \& Visser, A. (2009). The relationship between academics' conceptions of knowledge, research and teaching - a metaphor study. Teaching in Higher Education, 14(6), 673-686. 